\title{
NOTCHI is a poor prognostic factor for breast cancer and is associated with breast cancer stem cells
}

This article was published in the following Dove Press journal:

OncoTargets and Therapy

7 November 2016

Number of times this article has been viewed

\author{
Ying Zhong' \\ Songjie Shen' \\ Yidong Zhou' \\ Feng Mao' \\ Yan Lin' \\ Jinghong Guan' \\ Yali Xu' \\ Shu Zhang ${ }^{2}$ \\ $\mathrm{Xu} \mathrm{\text {Liu } ^ { 3 }}$ \\ Qiang Sun' \\ 'Department of Breast Disease, \\ ${ }^{2}$ Department of Dermatology, Peking \\ Union Medical College Hospital, \\ ${ }^{3}$ Centralab Institute of Basic Medical \\ Sciences, Chinese Academy of \\ Medical Sciences, Beijing, People's \\ Republic of China
}

\begin{abstract}
Recently, the human gene NOTCHI has been found to be implicated in cancer cell metastasis and the maintenance of cancer stem cells. However, for breast cancer in particular, an association between NOTCH1 levels and metastasis has not been determined. In this study, we investigated the expression status and correlation of NOTCH1 with clinically important factors related to metastasis and the cancer stem cell marker ALDH1. NOTCH1 and ALDH1 levels in 115 tumor tissues from primary lesions were determined by immunohistochemical staining. Most tissues were stained positive for both NOTCH1 and ALDH1, and NOTCH1 positivity was significantly associated with ALDH1 levels. NOTCH1 levels were significantly associated with TNM stage, metastasis, and triple-negative breast cancer. Moreover, both univariate and multivariate regression analyses revealed that basal-like features and NOTCH1 positivity were associated with disease-free survival as independent predictors. These analyses indicated that breast cancer patients testing positive for NOTCH1 had shorter disease-free survival. Our findings suggest that NOTCH1 may be involved in metastasis and is closely correlated with breast cancer stem cells.
\end{abstract}

Keywords: breast cancer, NOTCH1, metastasis, ALDH1, cancer stem cell

\section{Introduction}

NOTCH signaling plays an important role in angiogenesis, which is essential for the growth, progression, and metastasis of a tumor. ${ }^{1}$ The malignant cells undergo angiogenesis by secreting angiogenic factors and proteolytic enzymes to activate endothelial cell proliferation and migration and establish capillary networks. This irregular and ill-organized capillary network provides required metabolites to the growing tumor, and enables tumor cells to enter the circulation and form distant metastases. ${ }^{2}$ However, the precise mechanism underlying the promotion of cancer-cell migration, invasion, and metastasis through NOTCH signaling is not understood well.

NOTCH receptors and ligands are involved in tumorigenesis and coexpressed in tumor cells and the stromal compartment. ${ }^{3,4} \mathrm{NOTCH}$ receptors activated by ligands and expressed in adjacent cells have the potential to regulate cell-fate specification, differentiation, proliferation, and survival..$^{5}$ In several human cancers, NOTCH signaling is frequently dysregulated. Elevated concentrations of NOTCH receptors and their ligands relative to normal tissues have been demonstrated in the following cancers: cervical, colon, head and neck, lung, renal, pancreatic, acute myeloid, Hodgkin's disease, large-cell lymphomas, and breast. ${ }^{6-8}$

Furthermore, signals between neighboring cells through the NOTCH pathway can amplify and consolidate responses to intrinsic or extrinsic developmental changes. ${ }^{9}$ In (c) $\mathrm{NC}$ and incorporate the Creative Commons Attribution - Non Commercial (unported, v3.0) License (http:///reativecommons.org/licenses/by-nc/3.0/). By accessing the work you
hereby accept the Terms. Non-commercial uses of the work are permitted without any further permission from Dove Medical Press Limited, provided the work is properly attributed. For permission for commercial use of this work, please see paragraphs 4.2 and 5 of our Terms (https://www.dovepress.com/terms.php). 
human breast cancer MDA-M231 epithelial cells, knockdown of NOTCH1 led to significantly less extracellular matrix invasion, independently of its effects on cell proliferation and survival. This suggested a role for NOTCH signaling in regulating invasion. ${ }^{10}$ All this evidence indicates that higher levels of NOTCH1 support tumorigenesis via multiple mechanisms, ${ }^{4,11}$ yet here again the underlying molecular mechanisms are unknown.

It was previously found that NOTCH1 was mutated in a high percentage $(52 \%)$ of $\mathrm{CD} 4^{+} \mathrm{CD} 8^{+} \mathrm{T}$-cell tumors, resulting in higher levels of truncated NOTCH1 proteins. ${ }^{12}$ The results of that study indicated that NOTCH1 may be a frequent collaborator of $M Y C$, supporting oncogenesis. Moreover, the NOTCH1 gene is a target for mouse mammary tumor virus provirus insertional activation, which can transform $\mathrm{HC} 11$ mouse mammary epithelial cells in vitro. ${ }^{13} \mathrm{NOTCH} 1$ was also determined to be a mediator of Ras, a small cytoplasmic GTPbinding protein deregulated in many cancers, ${ }^{14}$ and NOTCH1 and JAG1 were coupregulated upon estrogen treatment not only in MCF7 breast cancer cells but also in endothelial cells. ${ }^{15}$ This suggested a role of NOTCH1-JAG1 in angiogenesis, tumor progression, and tumor metastasis. These data led us to hypothesize that NOTCH1 may be a potential differential biomarker for the prognosis of breast cancer patients. In the present study, we investigated the expression level of NOTCH1 in 115 breast cancer tissues and analyzed its correlation with known prognostic factors in breast cancer.

\section{Materials and methods}

\section{Patients and breast-tumor tissue samples}

A total of 115 patients diagnosed with breast cancer from 2000 to 2007 at Peking Union Medical College Hospital (PUMCH) were included. Ethical approval was obtained from the Peking Union Medical College Hospital and informed written consent was obtained. Tumor samples were embedded in paraffin for the diagnostic process. Postsurgical treatment of patients included one or more of the following: paclitaxel, anthracycline, CMF (cyclophosphamide, methotrexate, 5-fluorouracil) chemotherapy, tamoxifen, aromatase inhibitors, or radiation treatment. Recurrence was defined as chest-wall nodules or axillary lymph nodes. Metastasis was defined as bone, lung, liver, contralateral breast, brain, or supraclavicular lymph-node metastasis. The median follow-up was 23 months.

\section{Immunohistochemical analysis for NOTCHI and ALDHI}

Paraffin-fixed tissue sections were deparaffinized twice with xylene for 15 minutes and rehydrated with graded alcohols.
After endogenous peroxidase had been blocked with $3 \%$ hydrogen peroxide for 10 minutes, the slides were subjected to antigen retrieval for 5 minutes in a microwave oven in Tris-ethylenediaminetetraacetic acid buffer ( $\mathrm{pH}$ 9; Dako Denmark A/S, Glostrup, Denmark). Nonspecific binding was blocked by incubating the sections in normal goat serum. The slides were incubated with primary antibodies for NOTCH1 (rabbit polyclonal IgG, ab8925, 1:100 dilution; Abcam, Cambridge, UK) or ALDH1 (monoclonal IgG, 1:100 dilution; Abcam) at room temperature for 1 hour. The sections were washed with phosphate-buffered saline and then incubated with secondary antibody (ZSGB-Bio, Beijing, People's Republic of China) for 30 minutes. The sections were washed three times with phosphate-buffered saline, and visualized using ABC substrate buffer for 2 minutes. Tissue sections were counterstained with hematoxylin and dehydrated in an ascending graded series of ethanols (85\%-100\%). After xylene treatment, sections were mounted. Signs of the presence and levels of NOTCH1 or ALDH1, respectively, were detected using a Nikon Eclipse 80i microscope and an Mcv2000 image-analysis system.

\section{TNM stage, lymph-node status, and detection of HER2 and estrogen receptors and progesterone receptors}

Immunohistochemical (IHC) analyses of ER, PR, and HER2 were performed at a clinical laboratory in PUMCH hospital. Tumor-sections thickness was $5 \mu \mathrm{m}$, and sections were mounted on silicified slides. The levels of ER, PR, and HER2 were detected by routine methods. Each sample was stained with hematoxylin and eosin and histologically analyzed based on World Health Organization classification.

Tumor size and the number of lymph nodes were from pathology reports. The location of metastasis was detected by imaging examination and biopsy. Basal-like features were defined as negative for ER, PR, and HER2 expression based on IHC. The histologic grade was detected according to the Scarff-Bloom-Richardson grading system. The presence of ER and PR was considered positive when signs of these were detected in $\geq 1 \%$ of tumor cells. HER 2 expression was determined as IHC-positive when intense membrane staining was observed in $10 \%$ of invasive tumor cells, or fluorescence in situ hybridization (FISH) revealed more than six HER2 gene copies per nucleus or a FISH ratio (HER2 signal:chromosome 17 signal) $>2$.

\section{Assessment of recurrence and metastasis}

Recurrences were defined as tumors of the chest wall or axillary lymph nodes during follow-up. Metastases were defined 
as tumors of the bone, lung, liver, contralateral breast, brain, or supraclavicular lymph nodes during follow-up.

\section{Statistical analyses}

All statistical analyses were performed with SPSS software (version 17.0). NOTCH1 and ALDH1 results of IHC were associated with the various clinicopathologic parameters by $\chi^{2}$ and Mann-Whitney $U$-tests. An association between NOTCH1 and ALDH1 was assessed by Mann-Whitney $U$-test. Potential links between various parameters and metastasis were evaluated with logistic regression. All statistical tests were two-sided, and significance was defined as $P<0.05$.

\section{Results}

\section{Patient characteristics}

Of the 115 patients in this study, $105(90.4 \%)$ were given diagnoses of TNM stage II+III, while ten $(8.7 \%)$ patients were at TNM 0+I (Table 1). A total of 93 patients had axillary lymph-node metastases. The numbers of patients who tested positive for ER, PR, and HER2 were 48 (41.7\%), 54 (47\%), and 46 (40\%), respectively.

\section{NOTCHI-expression status}

IHC evidence of NOTCH1 was a dark-brown stain, both in the cytoplasm and nucleus of cells in the tumor tissues (Figure 1). A tissue with NOTCH1 evidence in $>1 \%$ of cells was classified as NOTCH1-positive; otherwise, the tissue was considered negative for NOTCH1. All slides were evaluated for NOTCH1 in cancer epithelial cells, but not stromal cells. The tissues of 102 patients $(88.7 \%)$ were considered positive for NOTCH1.

\section{Expression of ALDHI}

IHC evidence of ALDH1 was a brown stain in both the cytoplasm and nucleus of cells of the tumor tissues (Figure 2).

Table I Relationships between NOTCHI tumor cells or ALDHI tumor cells with clinicopathologic features $(\mathrm{N}=12 \mathrm{I})$

\begin{tabular}{|c|c|c|c|c|c|c|c|}
\hline \multirow[t]{2}{*}{ All cases } & \multirow[t]{2}{*}{$\mathbf{n}$} & \multicolumn{3}{|c|}{ NOTCHI expression in tumor cells } & \multicolumn{3}{|c|}{ ALDHI expression in tumor cells } \\
\hline & & $\begin{array}{l}\text { Negative } \\
\text { n (\%) }\end{array}$ & $\begin{array}{l}\text { Positive } \\
\text { n (\%) }\end{array}$ & $P$-value & $\begin{array}{l}\text { Negative } \\
\text { n (\%) }\end{array}$ & $\begin{array}{l}\text { Positive } \\
\text { n (\%) }\end{array}$ & $P$-value \\
\hline Tumor size & & & & 0.619 & & & 0.303 \\
\hline TI & 39 & $3(23.1)$ & $36(35.3)$ & & $16(28.6)$ & $23(39)$ & \\
\hline T2 & 62 & $9(69.2)$ & $53(52)$ & & $34(60.7)$ & $28(47.5)$ & \\
\hline T3 & 9 & $\mathrm{I}(7.7)$ & $8(7.8)$ & & $5(8.9)$ & $4(6.8)$ & \\
\hline T4 & 5 & 0 & $5(4.9)$ & & $\mathrm{I}(\mathrm{I} .8)$ & $4(6.8)$ & \\
\hline Lymph-node involvement & & & & 0.132 & & & 0.419 \\
\hline $\mathrm{LN}^{-}$ & 22 & $5(38.5)$ & $17(16.7)$ & & $9(16.1)$ & $13(22)$ & \\
\hline $\mathrm{LN}^{+}$ & 93 & $8(6 \mid .5)$ & $85(83.3)$ & & 47 (83.9) & $46(78)$ & \\
\hline TNM stage & & & & & & & 0.404 \\
\hline 0 & I & 0 & $I(I)$ & 0.267 & $\mathrm{I}(\mathrm{I} .8)$ & 0 & \\
\hline I & 9 & $2(15.4)$ & $7(6.9)$ & & $4(7.1)$ & $5(8.5)$ & \\
\hline II & 46 & $8(6 \mid .5)$ & $38(37.3)$ & & $19(33.9)$ & $27(45.8)$ & \\
\hline III & 58 & $3(23.1)$ & $55(53.9)$ & & $32(57.1)$ & $26(44.1)$ & \\
\hline IV & I & 0 & $I(I)$ & & 0 & I (I.7) & \\
\hline ER & & & & 1 & & & 0.099 \\
\hline- & 67 & $8(61.5)$ & $59(57.8)$ & & $37(66.1)$ & $30(50.8)$ & \\
\hline+ & 48 & $5(38.5)$ & $43(42.2)$ & & $19(33.9)$ & $29(49.2)$ & \\
\hline PR & & & & 0.082 & & & 0.793 \\
\hline- & 61 & $10(76.9)$ & $51(50)$ & & $29(51.8)$ & $32(54.2)$ & \\
\hline+ & 54 & $3(23.1)$ & $51(50)$ & & $27(48.2)$ & $27(45.8)$ & \\
\hline HER2 & & & & & & & 0.197 \\
\hline- & 69 & $9(69.2)$ & $60(58.8)$ & & $37(66.1)$ & $32(54.2)$ & \\
\hline+ & 46 & $4(30.8)$ & $42(4 \mid .2)$ & & $19(33.9)$ & $27(45.8)$ & \\
\hline Basal-like features & & & & 0.075 & & & 0.417 \\
\hline Present & 27 & $6(46.2)$ & $21(20.6)$ & & $15(26.8)$ & $12(20.3)$ & \\
\hline Absent & 88 & $7(53.8)$ & $81(79.4)$ & & $4 \mathrm{I}(73.2)$ & $47(79.7)$ & \\
\hline Recurrence & & & & 0.435 & & & 0.591 \\
\hline Absent & 55 & $10(90.9)$ & $45(76.3)$ & & $30(81.1)$ & $25(75.8)$ & \\
\hline Present & 15 & I (9.I) & 14 (23.7) & & 7 (I8.9) & $8(24.2)$ & \\
\hline Metastasis & & & & 0.035 & & & 0.222 \\
\hline Absent & & $10(83.3)$ & 45 (5I.I) & & $30(6 \mid .2)$ & $25(49)$ & \\
\hline Present & & $2(16.7)$ & $43(48.9)$ & & $19(38.8)$ & $26(5 \mathrm{I})$ & \\
\hline
\end{tabular}



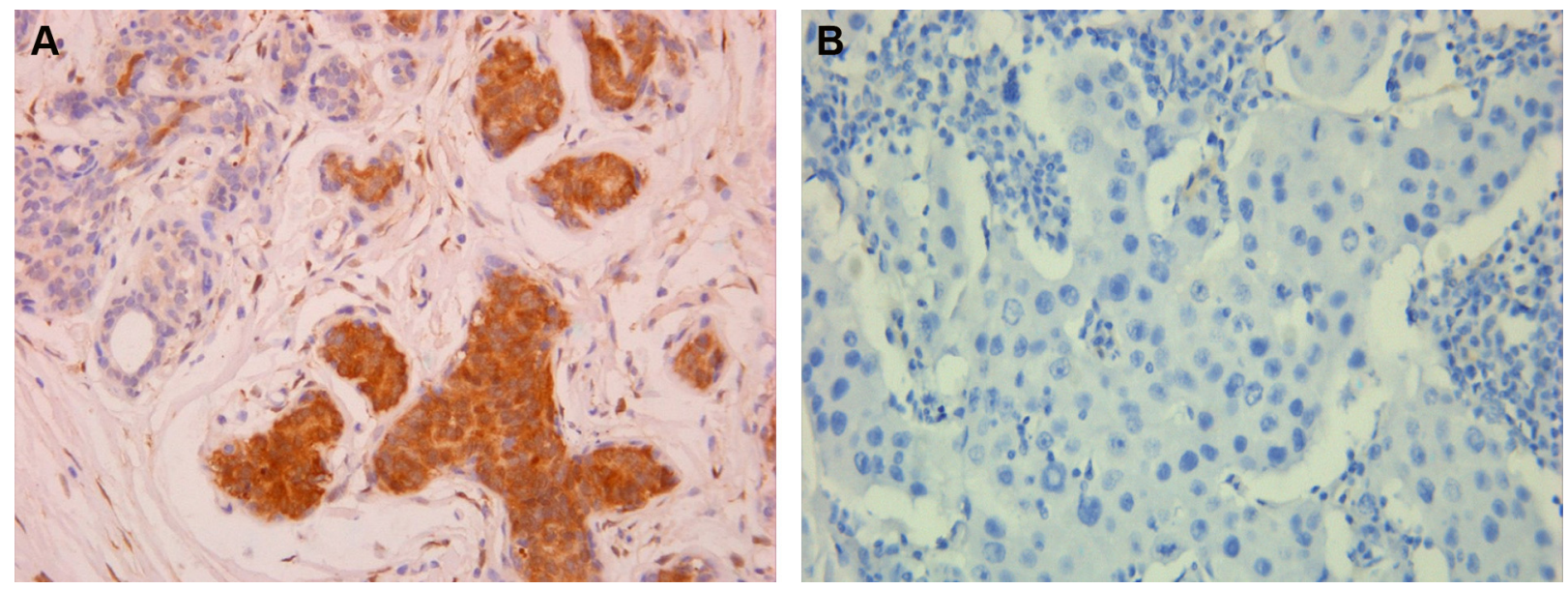

Figure I Immunohistochemical staining for ALDHI (400× magnification). Notes: (A) $\mathrm{ALDHI}^{+}$; (B) ALDHI-.

IHC staining results for ALDH1 were classified as $3+, 2+$, $1+$, or negative for $>50 \%, 10 \%-50 \%, 1 \%-10 \%$, and $<1 \%$ of cells, respectively. All slides were evaluated for ALDH1 in epithelial cells. The tissues of $59(51.3 \%)$ patients were considered positive for ALDH1.

\section{Associations of ALDHI or NOTCHI with clinicopathologic features of breast tumors}

Evidence of NOTCH1 in tumor tissue was significantly associated with TNM stage $(P=0.033)$ and metastasis $(P=0.041$, Table 1). The rate of recurrence or metastasis was $54.9 \%$ in the 115 patients. Evidence of NOTCH1 was significantly associated with a high metastasis rate $(P=0.035$; Figure $3 \mathrm{~A})$, but not with a high recurrence rate $(P=0.435$, Figure $3 \mathrm{~B})$. Most importantly, we found that the presence of NOTCH1 in tumor tissue was significantly associated with triple-negative breast cancer (TNBC; $P=0.041)$. No statistical association

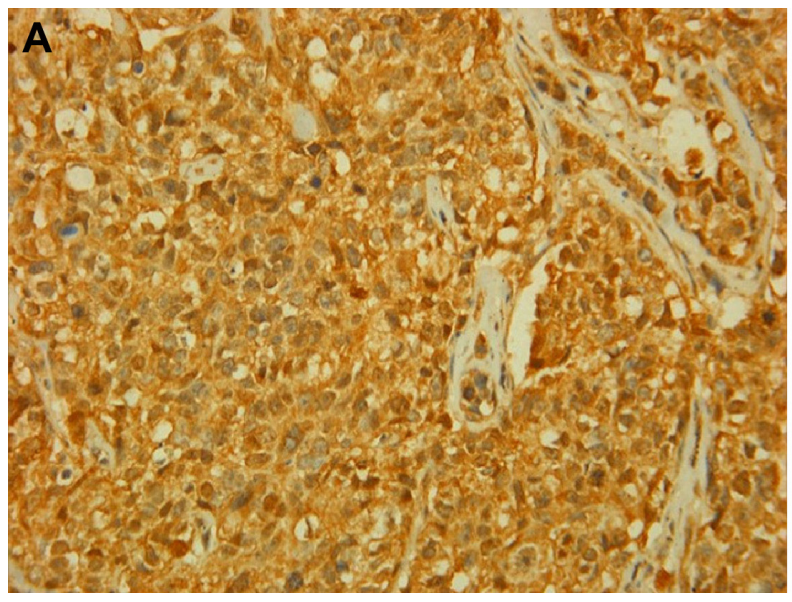

was observed between the presence of NOTCH1 in tumor tissue and other clinicopathologic features, such as tumor size, regional lymph nodes, recurrence, ER, PR, or HER2, nor was there any statistical association between ALDH1 in tumor tissues and the clinicopathologic characteristics tested, including TNM stage, regional lymph-node metastasis, distant metastasis, ER, PR, HER2, or basal-like features. Interestingly, the presence of NOTCH1 was significantly associated with ALDH1 status (Table 2), indicating that NOTCH1 may be closely associated with the advanced stages of breast cancer.

\section{Association between NOTCHI in tumor tissue and disease-free survival of breast cancer patients}

We investigated whether disease-free survival of breast cancer patients (ie, lack of metastasis or recurrence) may be related to NOTCH1 in tumor tissue, as well as with other

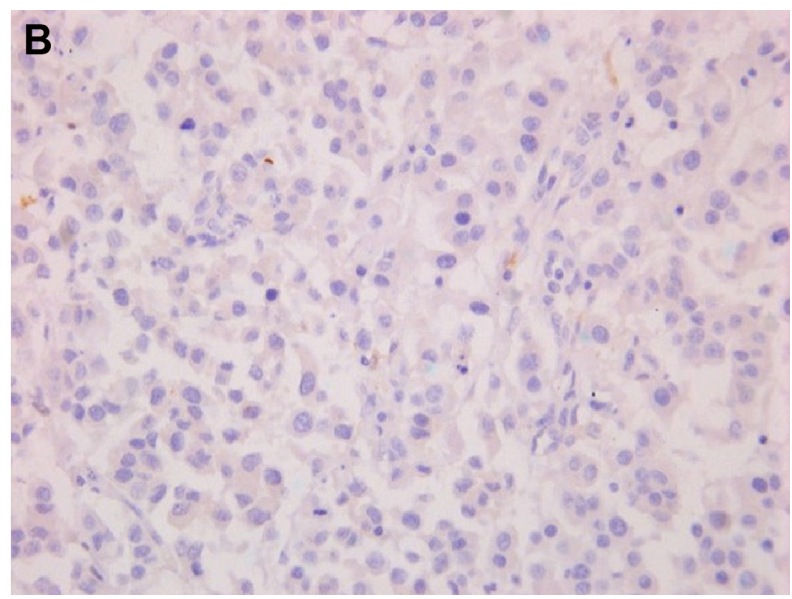

Figure 2 Immunohistochemical staining for NOTCHI (400× magnification). Notes: (A) NOTCHI+; (B) NOTCHI- 

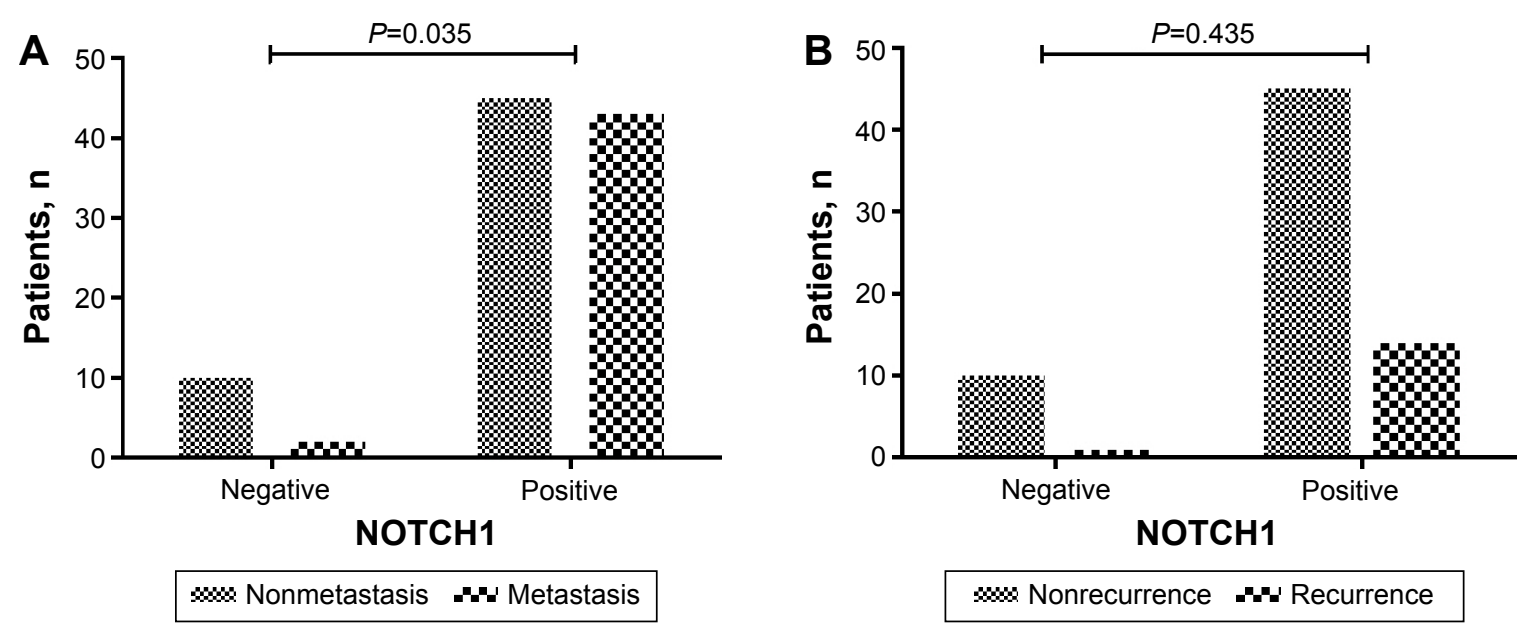

Figure 3 Relationship between NOTCHI and metastasis, recurrence.

Notes: (A) Association between NOTCHI positivity and metastasis. The number of patients with and without metastasis according to presence of NOTCHI in tumor tissues. P-values from $\chi^{2}$ tests are shown. (B) Association between NOTCHI positivity and recurrence. The number of patients with and without recurrence according to presence of NOTCHI in tumor tissues. $P$-values from $\chi^{2}$ tests are shown.

prognostic factors, such as lymph-node status, basal-like features, ER, PR, and HER2 (Table 3). Both univariate and multivariate regression analyses showed that basal-like features and the presence of NOTCH1 were independent predictors of disease-free survival. These analyses suggested that breast cancer patients whose tumor tissues tested positive for NOTCH1 had shorter disease-free survival.

\section{Discussion}

In this study, we showed that in 115 primary breast cancer samples, IHC evidence of NOTCH1 was significantly associated with TNM stage and metastasis. Positive evidence of NOTCH1 in tumor tissue was significantly associated with ALDH1 status, a marker of cancer stem cells, and correlated with TNBC. Moreover, both univariate and multivariate regression analyses revealed that basal-like features and NOTCH1 were independent predictors of disease-free survival. These analyses suggest that breast cancer patients with IHC evidence of NOTCH1 in tumor tissues have shorter disease-free survival.

We found a significant association between the presence of NOTCH1 in tumor tissue and TNM stage. Our results are consistent with recent observations that tumor grade and node status significantly correlate with NOTCH1 cytoplasmic expression in vitro and in archival specimens. ${ }^{10}$ Moreover, Reedijk et $a{ }^{16}$ showed that breast cancer patients with high levels of NOTCH1 had significantly poorer overall survival than those with tumors with low levels of NOTCH1. In our study, univariate and multivariate analyses showed that the presence of NOTCH1 was significantly associated with disease-free survival. Therefore, evidence of NOTCH1 in breast cancer tumor tissue, detected by routine IHC on paraffin sections in a hospital pathology laboratory, may indicate a poorer prognosis for the patient.

Mutations in such genes as NOTCH, Hedgehog, and $W N T$, which encode proteins involved in crucial signaling pathways for stem cells, may cause uncontrolled proliferation, thereby promoting tumorigenesis. Increased levels of NOTCH have been found in breast cancer, initiating cell populations characterized by the markers $\mathrm{CD} 44^{+} / \mathrm{CD} 24^{-}$, and linked to tumor-initiating properties and cancer stem cell-like invasive features. ${ }^{17}$ The NOTCH intracellular domain impairs the self-renewal of mammary stem cells $\left(\mathrm{CD} 24^{+} \mathrm{CD} 29^{\text {high }}\right)$ and facilitates their transformation through

Table 2 Univariate and multivariate analyses of various predictors of disease-free survival

\begin{tabular}{|c|c|c|c|c|c|}
\hline \multirow[t]{2}{*}{ Variable } & \multirow{2}{*}{$\begin{array}{l}\text { Metastasis/recurrence } \\
\text { rate }(\%)\end{array}$} & \multicolumn{2}{|c|}{ Univariate analysis } & \multicolumn{2}{|c|}{ Multivariate analysis } \\
\hline & & Odds ratio & $P$-value & Odds ratio & $P$-value \\
\hline Lymph-node involvement & $50 / 56$ & 0.785 & 0.61 & & \\
\hline $\mathrm{ER}^{-1+}$ & $61.1 / 46$ & 1.845 & 0.1 & & \\
\hline $\mathrm{PR}^{-1+}$ & $59.4 / 50$ & 1.462 & 0.301 & & \\
\hline HER $2^{-l+}$ & $56.8 / 52.1$ & 1.208 & 0.614 & & \\
\hline Basal-like features (present/absent) & $72.4 / 49.5$ & 2.682 & 0.031 & 4.118 & 0.01 \\
\hline NOTCHI ${ }^{-/+}$ & $23.1 / 55.9$ & 0.237 & 0.026 & 0.139 & 0.01 \\
\hline
\end{tabular}


Table 3 Relationship of ALDHI expression with NOTCHI expression

\begin{tabular}{lllll}
\hline NOTCHI & \multicolumn{3}{l}{ Grading of ALDHI } & P-value \\
\cline { 2 - 4 } & $\mathbf{0}$ & $\mathbf{I}+$ & $\mathbf{2 + / 3 +}$ & \\
\hline- & $\mathrm{I} 2$ & $\mathrm{I}$ & 0 & $0.00 \mathrm{I}$ \\
+ & 44 & 45 & 13 & \\
\hline
\end{tabular}

a cyclin $\mathrm{D}_{1}$-dependent pathway. ${ }^{18}$ Moreover, the HER2 promoter contains NOTCH-RBPJK-binding sequences ${ }^{19}$ that can be activated by NOTCH1 signaling and increase HER 2 transcription in both mammary stem/progenitor cells $\mathrm{s}^{20,21}$ and breast cancer stem cells. Therefore, NOTCH1 is related to the self-renewal of breast cancer stem cells. ${ }^{22}$ It has been shown that NOTCH1 interacts with erythropoietin (Epo) to maintain the self-renewing ability of breast cancer stem cells, which express Epo receptors on the surface. ${ }^{23}$ Accordingly, recombinant human Epo increased the numbers of breast cancer stem cells and self-renewing activity in a NOTCHdependent manner through induction of JAG1. ${ }^{23}$

ALDH is a marker that is commonly used to isolate stem cells, particularly cancer stem cells. It was reported that NOTCH signaling activated ALDH1A1 through the induction of SIRT2, leading to ALDH1A1 deacetylation and enzymatic activation to promote breast cancer stem cells. ${ }^{24}$ In agreement with previous observations that NOTCH receptors, ligands, or both correlated with cancer stem cells in several cancer types, including breast cancer stem cells, ${ }^{21,25-27}$ in the present study NOTCH1 was significantly associated with levels of ALDH1 in breast tumor tissue. Our results suggest that NOTCH1 may maintain the stemness of breast cancer stem cells via ALDH1 signaling.

TNBC is characterized by lack of ER, PR, and HER2. This difficult-to-treat form of breast cancer shows an undesirable tendency to overcome drug effectiveness..$^{28,29}$ Breast cancer stem cells are thought responsible for the development of drug resistance and relapse of TNBC. ${ }^{30}$ TNBC frequently expresses $\mathrm{CD} 44^{+} / \mathrm{CD} 24^{-}$, which is associated with a "stem cell" phenotype, resistance to conventional treatment, and repopulation of the cancer. Breast cancer stem cells have been shown to have specific molecular alterations, including activation of the NOTCH pathway. ${ }^{31,32}$ In addition, NOTCH mutations are frequently found in TNBC..$^{33}$ In our study, we found that NOTCH1 was significantly associated with TNBC. In addition, $\gamma$-secretase inhibitors were found to reduce the growth and dissemination of MDA-MB-231 TNBC xenografts. ${ }^{34}$ These facts suggest that activation of the NOTCH pathway is a key event in TNBC etiology, and targeting the $\mathrm{NOTCH}$ pathway may attenuate the drug resistance of TNBC patients.

In conclusion, we showed that NOTCH1 was highly expressed in breast tumors. NOTCH1 expression was significantly associated with metastasis and TNM stage, disease-free survival, and the expression of ALDH1 in breast cancers. Our results suggest that NOTCH1 has important roles in tumorigenesis and is a biomarker for the prognosis of breast cancer.

\section{Disclosure}

The authors report no conflicts of interest in this work.

\section{References}

1. Hanahan D, Weinberg RA. Hallmarks of cancer: the next generation. Cell. 2011;144(5):646-674.

2. Prager GW, Poettler M. Angiogenesis in cancer: basic mechanisms and therapeutic advances. Hamostaseologie. 2012;32(2):105-114.

3. Bridges E, Oon CE, Harris A. Notch regulation of tumor angiogenesis. Future Oncol. 2011;7(4):569-588.

4. Guo S, Liu M, Gonzalez-Perez RR. Role of Notch and its oncogenic signaling crosstalk in breast cancer. Biochim Biophys Acta. 2011;1815(2): 197-213.

5. Borggrefe T, Oswald F. The Notch signaling pathway: transcriptional regulation at Notch target genes. Cell Mol Life Sci. 2009;66(10): 1631-1646.

6. Kopan R, Ilagan MX. The canonical Notch signaling pathway: unfolding the activation mechanism. Cell. 2009;137(2):216-233.

7. Miele L. Notch signaling. Clin Cancer Res. 2006;12(4):1074-1079.

8. Miele L, Miao H, Nickoloff BJ. NOTCH signaling as a novel cancer therapeutic target. Curr Cancer Drug Targets. 2006;6(4):313-323.

9. Artavanis-Tsakonas S, Rand MD, Lake RJ. Notch signaling: cell fate control and signal integration in development. Science. 1999; 284(5415):770-776.

10. Rizzo P, Miao H, D'Souza G, et al. Cross-talk between notch and the estrogen receptor in breast cancer suggests novel therapeutic approaches. Cancer Res. 2008;68(13):5226-5235.

11. Miele L, Osborne B. Arbiter of differentiation and death: Notch signaling meets apoptosis. J Cell Physiol. 1999;181(3):393-409.

12. Girard L, Hanna Z, Beaulieu N, et al. Frequent provirus insertional mutagenesis of Notch1 in thymomas of MMTVD/Myc transgenic mice suggests a collaboration of c-Myc and Notch1 for oncogenesis. Genes Dev. 1996;10(15):1930-1944.

13. Dievart A, Beaulieu N, Jolicoeur P. Involvement of Notch1 in the development of mouse mammary tumors. Oncogene. 1999;18(44): 5973-5981.

14. Weijzen S, Rizzo P, Braid M, et al. Activation of Notch-1 signaling maintains the neoplastic phenotype in human Ras-transformed cells. Nat Med. 2002;8(9):979-986.

15. Soares R, Balogh G, Guo S, Gärtner F, Russo J, Schmitt F. Evidence for the Notch signaling pathway on the role of estrogen in angiogenesis. Mol Endocrinol. 2004;18(9):2333-2343.

16. Reedijk M, Odorcic S, Chang L, et al. High-level coexpression of JAG1 and NOTCH1 is observed in human breast cancer and is associated with poor overall survival. Cancer Res. 2005;65(18):8530-8537.

17. Farnie G, Clarke RB. Mammary stem cells and breast cancer: role of Notch signalling. Stem Cell Rev. 2007;3(2):169-175.

18. Ling H, Sylvestre JR, Jolicoeur P. Notch1-induced mammary tumor development is cyclin D1-dependent and correlates with expansion of premalignant multipotent duct-limited progenitors. Oncogene. 2010;29(32): $4543-4554$. 
19. Chen Y, Fischer WH, Gill GN. Regulation of the ERBB-2 promoter by RBPJк and NOTCH. J Biol Chem. 1997;272(22):14110-14114.

20. Politi K, Feirt N, Kitajewski J. Notch in mammary gland development and breast cancer. Semin Cancer Biol. 2004;14(5):341-347.

21. Dontu G, Jackson KW, McNicholas E, Kawamura MJ, Abdallah WM, Wicha MS. Role of Notch signaling in cell-fate determination of human mammary stem/progenitor cells. Breast Cancer Res. 2004;6(6): R605-R615.

22. Magnifico A, Albano L, Campaner S, et al. Tumor-initiating cells of HER2positive carcinoma cell lines express the highest oncoprotein levels and are sensitive to trastuzumab. Clin Cancer Res. 2009;15(6):2010-2021.

23. Phillips TM, Kim K, Vlashi E, McBride WH, Pajonk F. Effects of recombinant erythropoietin on breast cancer-initiating cells. Neoplasia. 2007;9(12):1122-1129.

24. Zhao D, Mo Y, Li MT, et al. NOTCH-induced aldehyde dehydrogenase $1 \mathrm{~A} 1$ deacetylation promotes breast cancer stem cells. $J$ Clin Invest. 2014;124(12):5453-5465.

25. Harrison H, Farnie G, Howell SJ, et al. Regulation of breast cancer stem cell activity by signaling through the Notch 4 receptor. Cancer Res. 2010;70(2):709-718.

26. Sansone P, Storci G, Giovannini C, et al. p66Shc/Notch-3 interplay controls self-renewal and hypoxia survival in human stem/progenitor cells of the mammary gland expanded in vitro as mammospheres. Stem Cells. 2007;25(3):807-815.

27. Cui J, Li P, Liu X, Hu H, Wei W. Abnormal expression of the Notch and $\mathrm{Wnt} / \beta$-catenin signaling pathways in stem-like $\mathrm{ALDH}{ }^{\mathrm{hi}} \mathrm{CD} 44^{+}$cells correlates highly with Ki-67 expression in breast cancer. Oncol Lett. 2015;9(4):1600-1606.
28. Jaspers JE, Rottenberg S, Jonkers J. Therapeutic options for triplenegative breast cancers with defective homologous recombination. Biochim Biophys Acta. 2009;1796(2):266-280.

29. Chen JQ, Russo J. ER $\alpha$-negative and triple negative breast cancer: molecular features and potential therapeutic approaches. Biochim Biophys Acta. 2009;1796(2):162-175.

30. Fillmore CM, Kuperwasser C. Human breast cancer cell lines contain stem-like cells that self-renew, give rise to phenotypically diverse progeny and survive chemotherapy. Breast Cancer Res. 2008;10(2):R25.

31. Berrada N, Delaloge S, André F. Treatment of triple-negative metastatic breast cancer: toward individualized targeted treatments or chemosensitization? Ann Oncol. 2010;21 Suppl 7:vii30-vii35.

32. Zhu H, Bhaijee F, Ishaq N, et al. Correlation of Notch1, pAKT and nuclear NF-KB expression in triple negative breast cancer. Am J Cancer Res. 2013;3(2):230-239.

33. Wang K, Zhang Q, Li D, et al. PEST domain mutations in Notch receptors comprise an oncogenic driver segment in triple-negative breast cancer sensitive to a $\gamma$-secretase inhibitor. Clin Cancer Res. 2015;21(6) 1487-1496.

34. Zhang CC, Pavlicek A, Zhang Q, et al. Biomarker and pharmacologic evaluation of the $\gamma$-secretase inhibitor PF-03084014 in breast cancer models. Clin Cancer Res. 2012;18(18):5008-5019.
OncoTargets and Therapy

\section{Publish your work in this journal}

OncoTargets and Therapy is an international, peer-reviewed, open access journal focusing on the pathological basis of all cancers, potential targets for therapy and treatment protocols employed to improve the management of cancer patients. The journal also focuses on the impact of management programs and new therapeutic agents and protocols on

\section{Dovepress}

patient perspectives such as quality of life, adherence and satisfaction. The manuscript management system is completely online and includes a very quick and fair peer-review system, which is all easy to use. Visit http://www.dovepress.com/testimonials.php to read real quotes from published authors. 